Provided for non-commercial research and education use. Not for reproduction, distribution or commercial use.

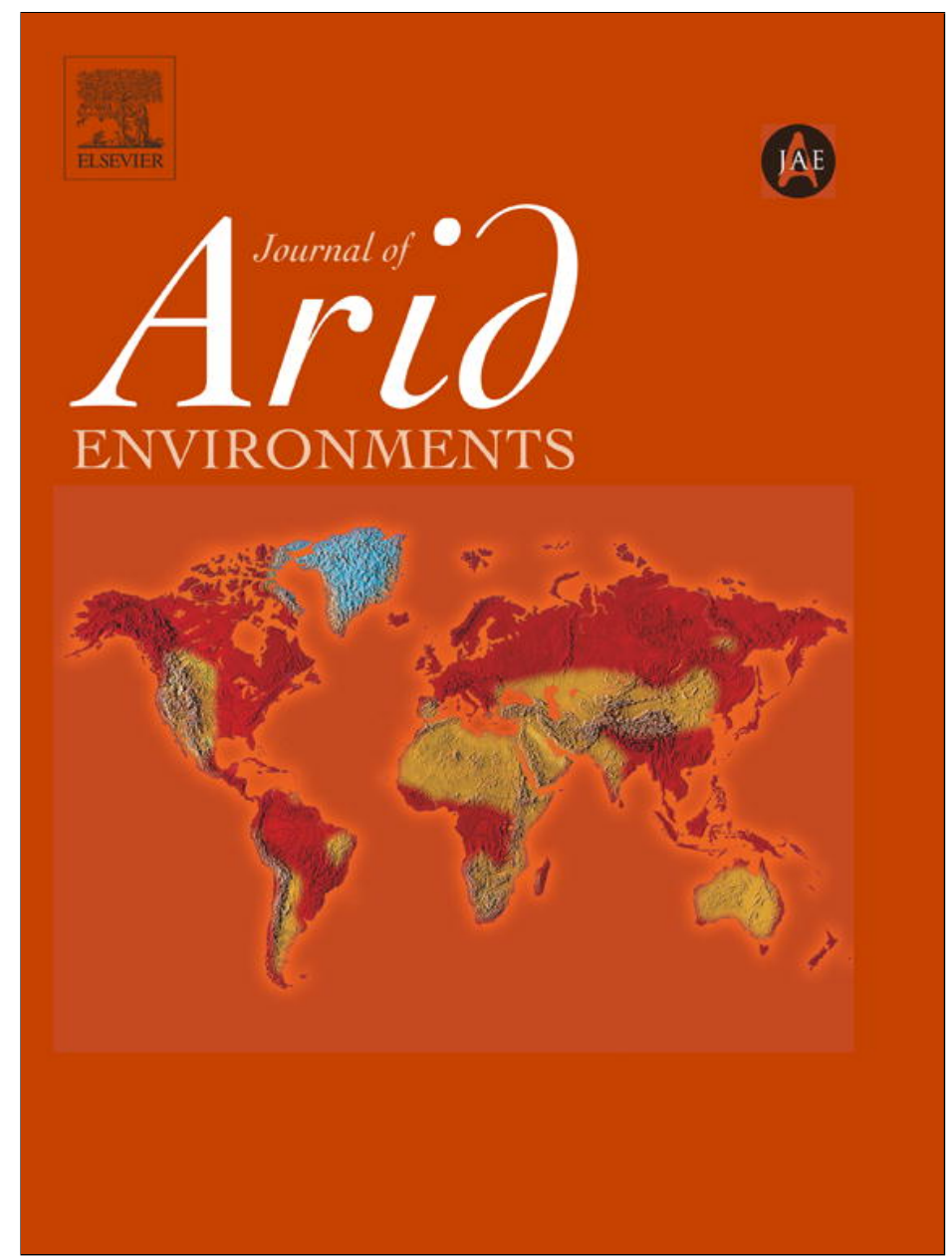

(This is a sample cover image for this issue. The actual cover is not yet available at this time.)

This article appeared in a journal published by Elsevier. The attached copy is furnished to the author for internal non-commercial research and education use, including for instruction at the authors institution and sharing with colleagues.

Other uses, including reproduction and distribution, or selling or licensing copies, or posting to personal, institutional or third party websites are prohibited.

In most cases authors are permitted to post their version of the article (e.g. in Word or Tex form) to their personal website or institutional repository. Authors requiring further information regarding Elsevier's archiving and manuscript policies are encouraged to visit:

http://www.elsevier.com/copyright 


\title{
Litter decomposition rates of two grass species along a semi-arid grassland-forest ecocline
}

\author{
L.H. Fraser*, A.D. Hockin \\ Dept. of Natural Resource Science, Thompson Rivers University, 900 McGill Road, Kamloops, BC V2C 5N3, Canada
}

\section{A R T I C L E I N F O}

\section{Article history:}

Received 3 February 2012

Received in revised form

17 July 2012

Accepted 20 July 2012

Available online

\section{Keywords:}

Climate change

Environmental gradient

Litter quality

Poaceae

\begin{abstract}
A B S T R A C T
The climatic controls on decomposition rates have gained considerable interest in recent years because of a perceived risk that elevated global temperatures could lead to positive green house gas feedbacks from soil ecosystems. Previous relationships between decomposition rates and abiotic variables like temperature and moisture have been proved confounding, particularly for dryland ecosystems. Decomposition rates of two grass species, Pseudoroegneria spicata (Pursh) Á. Löve and Calamagrostis rubescens Buckley, which represent dominant understory cover at either end of a semi-arid grassland to forest ecocline near Kamloops, British Columbia, Canada, were measured. Despite differences in \% $\mathrm{N}$ and $\mathrm{C}: \mathrm{N}$, decomposition rates between the two species were similar. Elevation was strongly correlated with rate of decomposition for both species. We provide evidence of a positive correlation of water availability and a negative correlation of temperature on decomposition rates along the elevational ecocline. Decomposition rates were higher during the wetter spring period than during summer, at higher elevations and in more mesic ecosystems. We found no 'home-field' advantage for P. spicata and C. rubescens on decomposition rates. Our results provide evidence that available moisture is an important control on decomposition rates in dryland ecosystems.
\end{abstract}

(ㄷ) 2012 Elsevier Ltd. All rights reserved.

\section{Introduction}

Approximately ninety percent of plant growth falls directly to the soil where it becomes available for decomposition and soil building (Beare et al., 1995). Decomposition is critical to terrestrial carbon cycling, soil formation and plant nutrient availability (Berg and McClaughtery, 2008). The strong apparent linkage between decomposition and climate has led to concerns that climatic change could accelerate global decomposition rates and a positive feedback of green house gasses (GHGs) to the atmosphere (Cao and Woodward, 1998; Kirschbaum, 1995; Trumbore and Chadwick, 1996). However, no clear consensus regarding the relationship between climate change and changes in short-term carbon pools exists (Aerts, 2006; Berg and Laskowski, 2005; Giardina and Ryan, 2000; Kirschbaum, 2006).

Abbreviations: B.C., British Columbia; BG, Bunchgrass prairie; $B W$, Weight of the oven dry paper bag; C:N, Carbon:Nitrogen; DF, Douglas fir forest; GHG, Green house gasses; IW, Initial weight of sample; \%M, Percent moisture; OVDW, Oven dry weight; T1, Time 1; T2, Time 2; $\bar{\chi} \% M$, Mean percent moisture.

* Corresponding author. Tel.: +1 250377 6135; fax: +1 2503776069

E-mail address: Lfraser@tru.ca (L.H. Fraser).
Decomposition rates in arid and semi-arid ecosystems have been particularly difficult to explain using climatic data, and the rate of decomposition appears to be either unrelated or related to temperature and available moisture (See for example: Elking et al., 1982; Kirschbaum, 1995; Throop and Archer, 2009; Vanderbilt et al., 2008; Whitford et al., 1981). Photodegradation, other abiotic activities (e.g., wind action) and the activity of microarthropods have been used to explain the apparent lack of linkage between climate and decomposition rates in arid ecosystems (Austin and Vivanco, 2006; Couteaux et al., 1995; Gallo et al., 2009). Given the wide variability in both causal and correlative factors outlined by a multitude of decomposition studies, ecosystemspecific approaches may better explain controls on decomposition rates. For example, several researchers have indicated that litter species may decompose faster in their native ecosystems where their specialized saprotrophs exist (Ayres et al., 2009; Gholz et al., 2000). This phenomenon has been referred to as a "homefield advantage".

Increased understanding of the variables that govern decomposition in drylands will help to further elucidate whether global climatic change is likely to increase GHGs releases from these ecosystems and will help to provide a better understanding of the processes that control nutrient cycling and soil building. 
Climatically derived ecoclines present a convenient way to study potential shifts in climate by substituting shifts in time with shifts in space. This is particularly relevant since predicted shifts in ecosystem range due to climate change are expected to directly influence ecoclines (Hamann and Wang, 2006). Our study used a climatically derived ecocline that transitioned from grassland to forest, rose over nearly $700 \mathrm{~m}$ in elevation and crossed three distinct plant community types along a gradient in increasing available moisture and decreased temperature. The overall objective of this study was to determine how decomposition rates of two grass species Pseudoroegneria spicata (Pursh) Á. Löve and Calamagrostis rubescens Buckley, that represent dominant understory cover at either end of the ecocline used, vary according to elevation and plant community, co-variates of climate.

We set out to test three hypotheses: (1) The species with a lower leaf C:N content or higher \% $\mathrm{N}$ will have a higher rate of decomposition (2) Decomposition rates will be positively correlated with elevation due to the fact that high elevation sites are wetter and cooler; and (3) Decomposition rates of $C$. rubescens and P. spicata will be greater in the ecosystems in which they are distributed; in other words, there will be a "home-field advantage".

\section{Materials and methods}

The study was conducted in the Dewdrop Range near Kamloops, British Columbia (B.C.), Canada. Slopes from the valley bottom in the Dewdrop Range lead to a clear altitudinal gradation in plant community types and a rapid grassland-to-forest ecocline. Across this ecocline, a transect was created from $50^{\circ} 45.323^{\prime} \mathrm{N}$; $120^{\circ} 37.433^{\prime} \mathrm{W}$ to $50^{\circ} 46.967^{\prime} \mathrm{N}$; $120^{\circ} 36.427^{\prime} \mathrm{W}$, and decomposition plots were established every $100 \mathrm{~m}(n=34)$ using a Trimble GeoXM global positioning system. We utilized the methods described by Lloyd et al. (1990), which categorize the plant communities in the Kamloops region using indicator species and physiographic variables (soil depth, slope angle, slope position, slope shape, elevation) and establishes 1955-1985 climate normals for each major community type. Ecosystem types along the transect ranged from lower elevation semi-arid bunchgrass (BG) prairie characterized by the absence of tree cover, to ponderosa pine (PP) savannah and temperate Douglas fir (DF) forest (Table 1).

Litter materials were collected 20 days prior to field deployment from within $7 \mathrm{~km}$ of the transect, from plots dominated by P. spicata (plot centered on $50^{\circ} 45.792 \mathrm{~N} ; 120^{\circ} 37.462 \mathrm{~W}$ ) or C. rubescens (plot centered on $50^{\circ} 45.745 \mathrm{~N} ; 120^{\circ} 31.532$ ). Senesced but still standing litter materials from the previous growing season was cut approximately $15 \mathrm{~cm}$ above the soil surface to avoid crown material and tillers that had been matted to the ground. Litter materials were allowed to air-dry indoors at approximately $22{ }^{\circ} \mathrm{C}$. Then $3.0000 \mathrm{~g}( \pm 0.0200 \mathrm{~g})$ of $P$. spicata or C. rubescens was placed in a $10 \mathrm{~cm} \times 10 \mathrm{~cm}$ pre-made litter bag of $1 \mathrm{~mm}$ hole size geotextile fabric. On April 22, 2009, immediately after the transect was free of snow cover, two litter bags of $P$. spicata and two of $C$. rubescens were deployed at each plot by pinning bags to the surface, on top of existing litter. An additional 12 bags of each species were reserved for determination of litter moisture content before field deployment (as described below). As well, six samples of each litter species were reserved for determination of C:N values. After oven drying, approx $5.0 \mathrm{mg}( \pm 0.5 \mathrm{mg})$ from each sample was ground in a standard coffee grinder, placed into a pre-weighed aluminum autosampler vial, reweighed to the nearest $\mathrm{mg}$, and analyzed for $\% \mathrm{C}$, $\% \mathrm{H}$ and \% $\mathrm{N}$ in a CE-440 elemental analyzer (Exeter Analytical, Inc.) using lysine as a calibration substance.

On June 21, $2009(T=1)$, one litter bag of each species was collected from each plot. On August 30, $2009(T=2)$, the two remaining bags (one of each species) were collected from each plot. Collected decomposition bags were placed in individual zip lock bags, brought to the lab and processed within $48 \mathrm{~h}$. Processing involved cutting open the litter bags, emptying litter materials into a Petri dish and removing any obvious contaminants (e.g., mineral soil or insects) under a hand lens. Cleaned litter materials were placed into an oven-dry, pre-weighed paper bag and weighed on an analytical balance to the nearest $0.1 \mathrm{mg}$ to determine wet weight. Processed litter materials were then placed in a drying oven at $60{ }^{\circ} \mathrm{C}$ for at least three days. Dry litter materials were then reweighed to determine dry weight.

Percent moisture $(\% M)$ was determined using the following formula: $100[(W W-B W)-(O V D W-B W)] /(O V D W-B W)$. Percent change in mass $(\% \Delta)$ was calculated as: $100(1-I W) /$ $(W W-B W)-\bar{\chi} \% \mathrm{M})$. Where $O V D W$ is the oven dry weight of the sample, $W W$ is the pre-oven dry weight of the sample, $B W$ is the weight of the oven dry paper bag used for sample storage, $I W$ is the initial weight of the sample before litter bag construction, and $\bar{\chi} \% \mathrm{M}$ is the mean percent moisture of litter bags reserved for determination of pre-field moisture content for that particular litter species. Percent change in mass per day was determined by dividing $\% \Delta$ by the number of days the sample was in the field.

Two unpaired two sample $t$-tests were done to test differences in leaf $\mathrm{C}: \mathrm{N}$ and \% $\mathrm{N}$ values between $P$. spicata and $C$. rubescens. Three linear regressions were applied to test the effect of (1) elevation on decomposition rates by species and by time; (2) elevation on percent moisture of litter bags by species and by time; and (3) percent moisture of litter bags on decomposition rates by species and by time. Two paired two sample $t$-tests were done to determine differences in decomposition rates between $P$. spicata and C. rubescens, and between sampling periods $\mathrm{T} 1$ and $\mathrm{T} 2$. To test the "home field advantage" hypothesis, a factorial 3-way ANOVA including ecosystem type, plant species, and time was applied to determine main and interacting effects on daily decomposition rates. All statistical analyses were performed in "R" (v2.11.1) (R Development Core Team, 2010). Statistical tests were performed on arcsine transformed data to satisfy the assumption that the data were normally distributed, but all values reported and graphed below are actual daily decomposition rates, not transformed values.

\section{Results}

Before deployment in the field, $C$. rubescens had a mean C: $N$ value of $72.89 \pm 9.43$ (mean \pm STD) and a $\mathrm{N}$ concentration of $0.51 \pm 0.05 \mathrm{~g} / \mathrm{kg}$; whereas, P. spicata had a C:N value of $57.79 \pm 9.07$ and a $\mathrm{N}$ concentration of $0.68 \pm 0.13 \mathrm{~g} / \mathrm{kg}$. An unpaired two sample

Table 1

Number of plots, elevation ranges and 1955-1985 temperature and precipitation normals across the three ecosystems used in this study. Temperature and precipitation data from Lloyd et al. (1990). Note that, a single Douglas fir (DF) plot occurred in a gully at the bottom of the transect and that otherwise bunchgrass (BG), ponderosa pine (PP) and DF sites occurred in strict elevational sequence.

\begin{tabular}{lllll}
\hline Ecosystem & Elevation $(\mathrm{m} \mathrm{ASL})$ & Number of plots & Annual precipitation $(\mathrm{mm})$ & Annual temperature $\left({ }^{\circ} \mathrm{C}\right)$ \\
\hline BG & $631-675$ & 7 & $285(160-458)$ & $7.9(4.4-10.0)$ \\
PP & $681-1013$ & 15 & $335(258-391)$ & $7.8(5.4-9.4)$ \\
DF & $585-1277$ & 12 & $476(295-843)$ & Dominant understory plant \\
\hline
\end{tabular}


$t$-test indicated significant differences between $\mathrm{C}: \mathrm{N}$ values $(t=-2.796, \mathrm{df}=5, n=6, p=0.019)$ and $\mathrm{g} / \mathrm{kg} \mathrm{N}$ concentrations $(t=3.308, \mathrm{df}=5, n=6, p=0.021)$. Paired two sample $t$-tests indicated no significant difference between mean decomposition rates for the two grass species during $T=1(t=-0.774, \mathrm{df}=31$, $n=32, p=0.444)$ or $T=2(t=0.140, \mathrm{df}=31, n=32, p=0.890)$. But, there were significantly different rates of decomposition between the $T=1$ and $T=2$ sample periods for both $C$. rubescens $(t=-13.628$, df $=31, n=32, p<0.001)$ and for $P$. spicata $(t=-9.3283, \mathrm{df}=31, n=32, p<0.001)$. Note that both $P$. spicata and $C$. rubescens bags from the $630 \mathrm{~m}$ ASL plot were chewed by rodents during $T=2$, and the $C$. rubescens bag was missing from the $661 \mathrm{~m}$ ASL plot at $T=2$. As such, only 32 decomposition plots were used in the above $t$-tests.

There was a significant increase in both decomposition rates (Fig. 1) and litter moisture content (Fig. 2) with elevation. Mean mass loss of $P$. spicata was $5.22 \%$ during $T=1$, with an additional $1.53 \%$ occurring at $T=2$. Mean mass loss of $C$. rubescens was $5.52 \%$ during $T=1$, with an additional $1.37 \%$ occurring during $T=2$. The equation of the regression line for both species considered together at $T=2\left(\% \Delta /\right.$ day $\left.=5 \times 10^{-5} \mathrm{~m} \mathrm{ASL}+0.011\right)$ predicted an increase in total mass loss of $0.67 \%$ per $100 \mathrm{~m}$ of elevation gain over the entire sample period. Mean moisture contents of $44 \%$ for $P$. spicata and $49 \%$ for $C$. rubescens were considerably higher and more variable across the elevation gradient at $T=1$ than at $T=2$, where mean moisture contents of $P$. spicata and C. rubescens were $7 \%$ and $8 \%$ respectively. Likewise, decomposition rates increased with litter moisture content for all treatments except for $C$. rubescens at $T=2$ (Fig. 3).
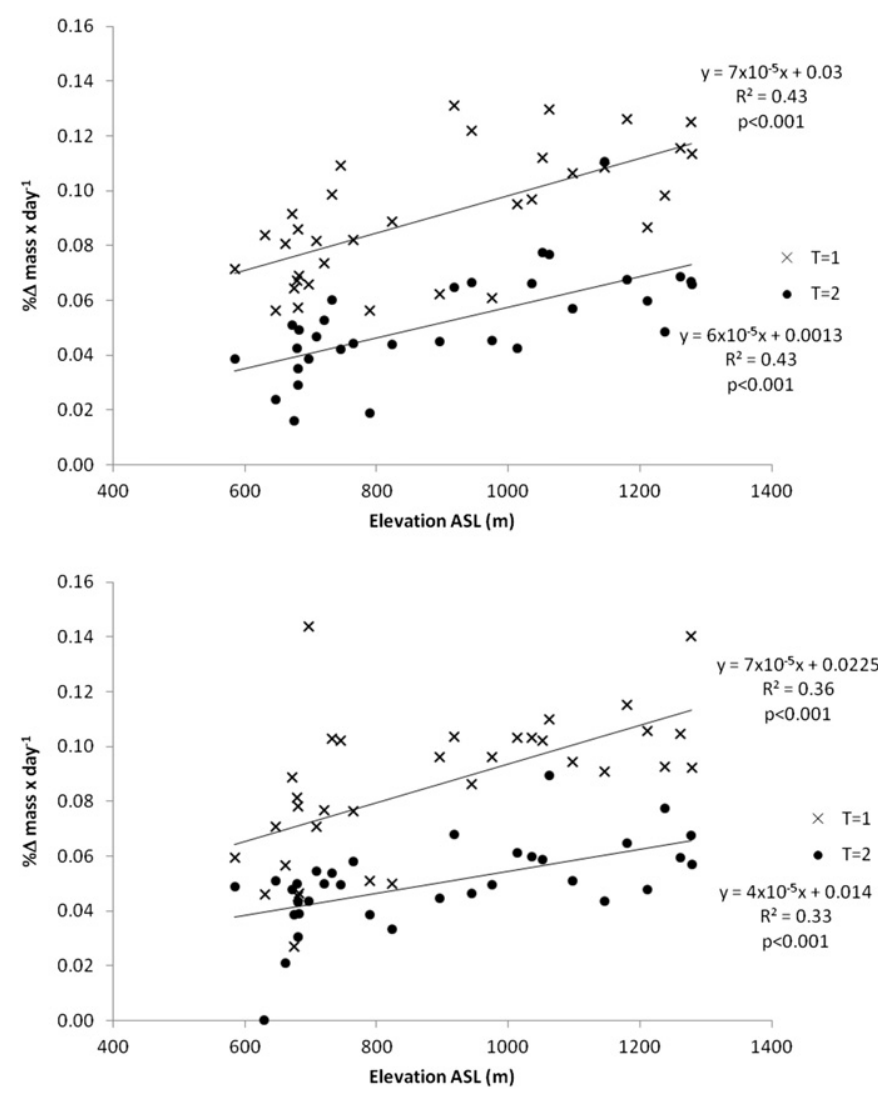

Fig. 1. Mean percent change in litter bag mass per day by elevation (ASL $=$ above mean sea level) for Pseudoroegneria spicata (top) and Calamagrostis rubescens (bottom). $T=1$ and $T=2$ refer to timing of sampling, June 21, 2009 and August 30,2009, respectively.
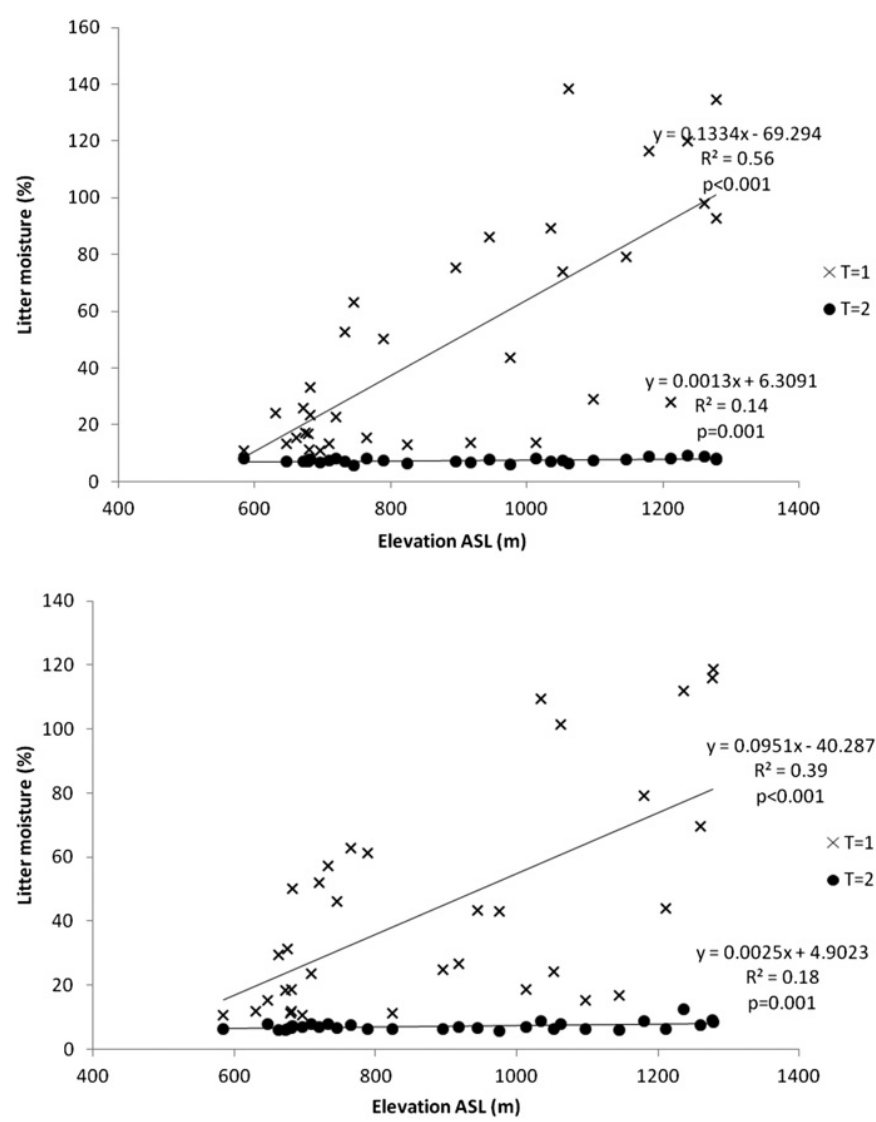

Fig. 2. Mean percent litter moisture, at collection time, by elevation (ASL = above mean sea level) for Pseudoroegneria spicata (top) and Calamagrostis rubescens (bottom). $T=1$ and $T=2$ refer to timing of sampling, June 21, 2009 and August 30, 2009, respectively.

A factorial ANOVA suggested that decomposition rates were significantly correlated with ecosystem type $\left(F_{2,132}=26.55\right.$, $p<0.0001)$ and season $\left(F_{1,132}=138.09, p<0.0001\right)$. However, there was no correlation between decomposition rates and grass species $\left(F_{1,132}=0.638, p=0.426\right)$, or for interactions between ecosystem and season $\left(F_{2,132}=0.446, p=0.641\right)$, ecosystem and grass species $\left(F_{2,132}=0.533, p=0.588\right)$, or season and grass species $\left(F_{1,132}=0.567, p=0.453\right)$. Given a lack of variation in decomposition rates for the two species, the average decomposition rate for both species combined was 33\% higher in Douglas fir ecosystems during the spring $\left(0.104 \pm 0.018 \%\right.$ day $\left.^{-1}\right)$ and $16 \%$ higher in ponderosa pine ecosystems $\left(0.083 \pm 0.025 \%\right.$ day $\left.^{-1}\right)$ as compared to bunchgrass ecosystems $\left(0.070 \pm 0.018 \%\right.$ day $\left.^{-1}\right)$. During the drier summer period, when both species are combined in a single population, decomposition rates were $41 \%$ higher in Douglas fir ecosystems $\left(0.064 \pm 0.016 \%\right.$ day $\left.^{-1}\right)$ and $20 \%$ higher in ponderosa pine ecosystems $\left(0.047 \pm 0.011 \%\right.$ day $\left.^{-1}\right)$ as compared to bunchgrass ecosystems $\left(0.038 \pm 0.013 \%\right.$ day $\left.^{-1}\right)$.

\section{Discussion}

Our results indicate that elevation is strongly positively correlated with decomposition rate and that available moisture exerts a significant control on decomposition rates, both spatially and temporally, in the temperate and semi-arid ecosystems of British Columbia's Southern Interior. Mass loss was higher in more mesic ecosystems, across the elevation gradient and in litter bags with higher moisture content. However, despite observed differences in 

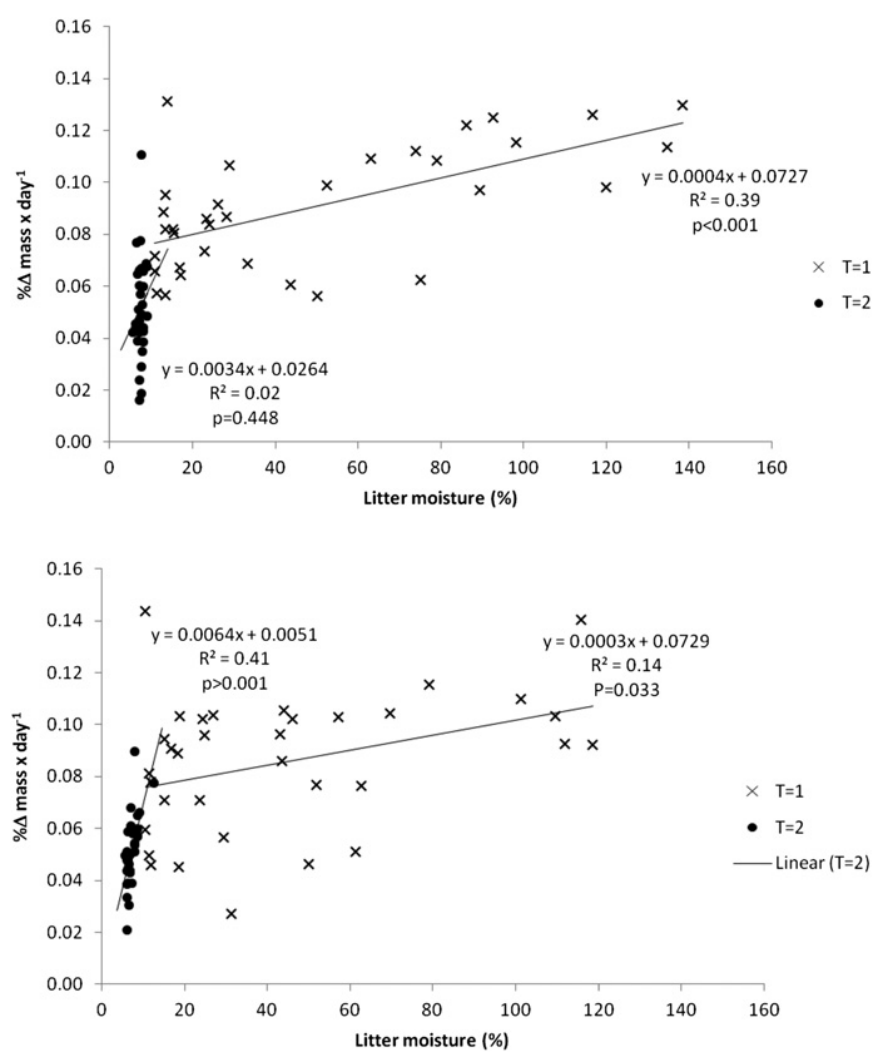

Fig. 3. Mean percent change in litter bag mass per day by mean percent litter moisture, at collection time for Pseudoroegneria spicata (top) and Calamagrostis rubescen (bottom). $T=1$ and $T=2$ refer to timing of sampling, June 21, 2009 and August 30, 2009, respectively.

litter quality between the two species used in this study, their decomposition rates were not statistically different. Thus, small differences in C: $\mathrm{N}$ ratio, may not make a given litter type more bioavailable. This indicates that the use of litter-type functional groups may be appropriate in decomposition studies. In our study area, where $P$. spicata is a dominant understory cover in lowland bunchgrass and ponderosa pine sites and $C$. rubescens is considerably more abundant in upland Douglas fir sites, shifts in the relative abundance of these two species may have minimal impact on ecosystem nutrient dynamics.

Mean litter moisture content, and consequently litter decomposition rates, were higher across the elevation gradient at $T=1$ (June 21, the relatively wet spring) compared to $T=2$ (August 30, the hot, dry summer). The thirty year rainfall average for June was calculated at $35.2 \mathrm{~mm}$, compared to August at $29.1 \mathrm{~mm}$ (Carlyle et al., 2011). The reduction in rainfall combined with an increase in temperature from June to August resulted in lower water availability in August across the elevation gradient. This explains the consistent low litter moisture, resulting in low variance, across the elevation gradient at $T=2$. It should be noted that while there was a significant relationship between litter moisture and elevation for both grass species at $T=2$, the $R^{2}$ values were less than 0.18 and therefore likely biologically meaningless.

We found no support for the hypothesis that litter quality or decomposer specificity, i.e. home-field advantage, led to different decomposition rates for $C$. rubescens and $P$. spicata. Other workers (Ayres et al., 2009; Gholz et al., 2000), have suggested that interand intra-specific dynamics between decomposers may explain the proportion of decomposition variability not explained by climate. Although decomposition rates were extremely similar between litter species, their morphologies are fairly different and they had definite but slight differences in litter quality. P. spicata is comprised of a considerably higher proportion of culm, whereas $C$. rubescens is comprised almost entirely of leaf material. Moreover, the $\mathrm{N}$ concentration of $C$. rubescens was $75 \%$ that of $P$. spicata. Nonetheless, differences in bioavailability or the species' ability to retain moisture content were negligible in determining rates of decomposition. However, if species, like pine needles, with considerably different biochemistry had been used, different decomposition rates would certainly have been observed (Prescott et al., 2004). Similar decomposition rates between $P$. spicata and $C$. rubescens suggests that the use of functional litter-groups could be a viable option in considering the dynamics of short-term $\mathrm{C}$ pools.

In a five-year litter bag experiment along a semi-arid Great Basin desert-scrub to ponderosa pine ecocline, Murphy et al. (1998) concluded that moisture, not temperature, was the dominant climatic control on decomposition rates. In the semi-arid grasslands of the Argentinean pampas, Torres et al. (2005) found that the majority of decomposition occurred during the wet season (summer, autumn). Likewise, in a ten-year decomposition study spread across the Great Plains of the United States, Bontti et al. (2009) concluded that decomposition rate by mean annual precipitation had a coefficient of determination $\left(R^{2}\right)$ of 0.86 . However, in a ten-year study along a Central New Mexico precipitation gradient, Vanderbilt et al. (2008) found that precipitation was not significantly correlated with decomposition rates. Likewise, in the Chihuahuan Desert, Cepeda-Pizarro and Whitford (1990) found that decomposition rates were not correlated with available moisture, but that termite activity exerted a strong control. As well, in Saskatchewan, Kochy and Wilson (1997) found that litter decomposition was higher in grassland plots than in adjacent aspen stands, and hypothesized that this was attributable to the impact of shading.

The wide body of contrasting results on the climatic controls on decomposition in dryland ecosystems indicates that simple temperature or moisture relationships are not applicable. This is likely because temperature and moisture do not adequately describe the complexities of decomposer food webs and the subtleties of physiochemical weathering. For example, working along a mesic to xeric gradient in a Colorado Artemisia community Shaw and Harte (2001) used infrared lamps to simulate climate warming. Their results indicated that elevated temperatures only increased decomposition rates during periods when soil moisture was not limiting. Moreover, they concluded that increased temperature could also promote soil drying, thereby shortening the time-span during which soil moisture levels were optimal for decomposition. Additionally, they surmised that the indirect impacts of warming by infrared lamps on plant communities and associated changes in litter quality could have a higher overall impact on decomposition rates than the direct effect of elevated temperature itself. The use of only temperature or only moisture to predict decomposition rates is inadequate, especially when developing predictions about soil GHG feedbacks due to climate change. However, given that available moisture appears to exert a dominant control on decomposition in many drylands, management activities (irrigation or dam building) may have a larger impact on atmospheric GHG concentrations than the effects of rising atmospheric temperatures.

Future climate envelope models developed for the southern interior of British Columbia indicate that drier ecosystem types found at valley bottoms will likely shift or expand their range to encompass higher elevation sites (Hamann and Wang, 2006). To extrapolate the results from our study, this would suggest that the bluebunch wheatgrass ecosystem type will expand and displace the ponderosa pine ecosystem type, and the ponderosa pine 
ecosystem type will likewise displace the Douglas fir ecosystem type. Although the shift in ecosystem types will result in changes in the dominant understory grass species, the change in species will likely not influence rates of decomposition at an ecosystem level. However, the cause of the predicted ecosystem shifts within the climate models is a result of increased drought. With an increase in drought, and a projected increase in semi-arid bunchgrass ecosystems, we predict decomposition rates of the two dominant grasses to be reduced in the southern interior of B.C. as a result of climate change.

\section{Acknowledgments}

Jennifer Zacher, Cameron Carlyle and Amanda Schmidt provided help with the deployment, collection and processing of litter bags. Financial support for this project was provided by a Natural Science and Engineering Research of Canada Discovery Grant and a BC Ministry of Forests, Lands and Natural Resource Operations Future Forest Ecosystems Scientific Council grant to LHF and a Thompson Rivers University Comprehensive Endowment Fund grant to AH.

\section{References}

Aerts, R., 2006. The freezer defrosting: global warming and litter decomposition rates in cold biomes. Journal of Ecology 94, 713-724.

Austin, A.T., Vivanco, L., 2006. Plant litter decomposition in a semi-arid ecosystems controlled by photodegradation. Nature 442, 555-558.

Ayres, E., Steltzer, H., Simmons, B.L., Simpson, R.T., Steinweg, J.M., Wallenstein, M.D., Mellor, N., Parton, W.J., Moore, J.C., Wall, D.H., 2009. Home-field advantage accelerates leaf litter decomposition in forests. Soil Biology and Biochemistry 41, 606-610.

Beare, M., Coleman, D., Crossley, D., Hendrix, P., Odum, E., 1995. A hierarchical approach to evaluating the significance of soil biodiversity to biogeochemical cycling. Plant and Soil 170, 5-22.

Berg, B., Laskowski, R., 2005. Climatic and geographic patterns in decomposition. In: Berg, B., Laskowski, R. (Eds.), Litter Decomposition: a Guide to Carbon and Nutrient Turnover; Advances in Ecological Research. London: Academic Press, New York, pp. 227-261.

Berg, B., McClaughtery, C., 2008. Plant Litter: Decomposition, Humus Formation, Carbon Sequestration. Springer-Verlag, New York.

Bontti, E.E., Decant, J.P., Munson, S.M., Gathany, M.A., Przeszlowska, A., Haddix, M.L., Owens, S., Burke, I.C., Parton, W.J., Harmon, M.E., 2009. Litter decomposition in grasslands of Central North America (US great plains). Global Change Biology $15,1356-1363$.

Cao, M., Woodward, F.I., 1998. Dynamic responses of terrestrial ecosystem carbon cycling to global climate change. Nature 393, 249-252.

Carlyle, C.N., Fraser, L.H., Turkington, R., 2011. Tracking soil temperature and moisture in a multi-factor climate experiment in temperate grassland: do climate manipulation methods produce their intended effects? Ecosystems 14, 489-502.
Cepeda-Pizarro, J., Whitford, W.G., 1990. Decomposition patterns of surface leaf litter of six plant species along a chihuahuan desert watershed. American Midland Naturalist 123, 319-330.

Couteaux, M., Bottner, P., Berg, B., 1995. Litter decomposition, climate and litter quality. Trends in Ecology and Evolution 10, 63-66.

Elking, N.Z., Steinberger, Y., Whitford, W.G., 1982. Factors affecting the applicability of the AET model for decomposition in arid environments. Ecology 63, $579-580$.

Gallo, M.E., Porras-Alfaro, A., Odenbach, K.J., Sinsabaugh, R.L., 2009. Photoacceleration of plant litter decomposition in an arid environment. Soil Biology and Biochemistry 41, 1433-1441.

Gholz, H.L., Wedin, D.A., Smitherman, S.M., Harmon, M.E., Parton, W.J., 2000. Longterm dynamics of pine and hardwood litter in contrasting environments: toward a global model of decomposition. Global Change Biology 6, 751-765.

Giardina, C.P., Ryan, M.G., 2000. Evidence that decomposition rates of organic carbon in mineral soil do not vary with temperature. Nature 404, 858-861.

Hamann, A., Wang, T., 2006. Potential effects of climate change on ecosystem and tree species distribution in British Columbia. Ecology 87, 2773-2786.

Kirschbaum, M.F., 1995. The temperature dependence of soil organic matter decomposition, and the effect of global warming on soil organic C storage. Soil Biology and Biochemistry 27, 753-760.

Kirschbaum, M.F., 2006. The temperature dependence of organic-matter decomposition-still a topic of debate. Soil Biology and Biochemistry 38, 2510-2518.

Kochy, M., Wilson, S.D., 1997. Litter decomposition and nitrogen dynamics in aspen forest and mixed-grass prairie. Ecology 78, 732-739.

Lloyd, D.A., Angove, K., Hope, G.D., Thompson, C., 1990. A Guide to Site Identification and Interpretation for the Kamloops Forest Region. BC Ministry of Forests, Victoria, British Columbia, Canada.

Murphy, K.L., Klopatek, J.M., Klopatek, C.C., 1998. The effects of litter quality and climate on decomposition along and elevation gradient. Ecological Applications 8, 1061-1071.

Prescott, C.E., Vesterdal, L., Preston, C.M., Simard, S.W., 2004. Influence of initial chemistry on decomposition of foliar litter in contrasting forest types in British Columbia. Canadian Journal of Forest Research 34, 1714-1729.

R Development Core Team, 2010. R: a Language and Development for Statistical Computing. v. 2.11.1. [Computer program].

Shaw, M.R., Harte, J., 2001. Control of litter decomposition in a subalpine meadowsagebrush steppe ecotone under climate change. Ecological Applications 11, 1206-1223.

Throop, H.L., Archer, S.R., 2009. Resolving the dryland decomposition conundrum: some new perspectives on potential drivers. In: Luttge, U., Beyschlag, W., Budel, B., Francis, D. (Eds.), Progress in Botany, vol. 70. Springer-Verlag, Berlin, pp. 171-194.

Torres, P.A., Abril, A.B., Bucher, E.H., 2005. Microbial succession in litter decomposition in the semi-arid chaco woodland. Soil Biology and Biochemistry 37, 49-54.

Trumbore, S.E., Chadwick, O.A., 1996. Rapid exchange between soil carbon and atmospheric carbon dioxide driven by temperature change. Science 272 , 393-396.

Vanderbilt, K.L., White, C.S., Hopkins, O., Craig, J.A., 2008. Aboveground decomposition in arid environments: results of a long-term study in central New Mexico. Journal of Arid Environments 72, 696-709.

Whitford, W.G., Meetenmeyer, V., Seastedt, T.R., Cromack, K., Crossley, D.A., Santos, P., Todd, R.L., Wade, J.B., 1981. Exceptions to the AET model: desserts and clear-cut forest. Ecology 62, 275-277. 